\title{
Gestational Exposure to Cadmium and Dimethoate Mixture Modifies Fetal Programming in Rats During Development
}

\author{
F. Anselmo, D. F. Horta, A. F. Godinho
}

\section{ABSTRACT}

The combined effects of environmental agents, as metals and pesticides, on human health, need be evaluated because human exposition occurs generally through mixtures, while regulatory assessment of neurotoxicity by these compounds is currently performed only on selected single substances. In the present study the effects of maternal exposure to $10 \mathrm{mg}$ cadmium/l (as cadmium acetate) in drinking water and dimethoate $4 \mathrm{mg} / \mathrm{kg}$ (via gavage) during gestation on the development of motor activity (locomotion and motor coordination) and social behavior (anxiety-like behavior and aggressivity) were studied. The importance of the cholinergic system in the modulation of behaviors was studied using acetylcholinesterase (AChE) activity as a biomarker of effect. Cadmium (Cd) and dimethoate (DM) single exposition modified fetal programing for motor activity and social behavior at childhood and adulthood and leads to disturbs of the AChE activity. Exposition to the mixture of $\mathrm{Cd}$ and DM enhanced effects on fetal programing and $\mathrm{AChE}$ activity. The present results provide, for the first time, direct experimental evidence supporting that joint exposure to cadmium and dimethoate in uterus of rats seems additive and it is perturbs offspring development leading to harmful consequences on motor activity and social behavior, probably related to modulation of the cholinergic system. Our data suggest that added precautions regarding gestational exposure to metals and pesticide mixtures would be prudent to avoid the possibility of fetal programming.

Keywords: acetylcholinesterase activity, behavior, cadmium, development, dimethoate, fetal programming.

\section{INTRODUCTION}

In the last decades relevant progress has been made in the study of relation between environmental contaminants and adverse effects in human health. Metals and organophosphate insecticides are two classes of environmental emerging contaminants that have been causing concerns about risk evaluation in public health. Cadmium and dimethoate are important compounds of these classes due to increased rate of production, utilization and liberation for the environment. In recent years, these compounds are being individually studied and their actions on neurobehavioral activity have been reported in the current literature.

Cadmium is a metal toxicologically important because its organism half-life is 10-30 years mainly because of its low excretion rate from the body. Humans can be easily exposed to it through contaminated environment, occupational activities, and socially by smoking. Therefore, prolonged exposure to it has been linked to many toxic effects since it
Published Online: September 5, 2020

ISSN: $2593-8339$

DOI: $10.24018 /$ ejmed.2020.2.5.436

\section{F. Anselmo*}

São Paulo State University - UNESP, Botucatu, SP, Brazil.

(e-mail: anselmof_unesp@yahoo.com.br) D. F. Horta

São Paulo State University - UNESP,

Botucatu, SP, Brazil.

(e-mail:danielhorta@uol.com.br)

A. F. Godinho

São Paulo State University - UNESP, Botucatu, SP, Brazil.

(e-mail: af.godinho@ unesp.br)

*Corresponding Author accumulates over time in a variety of structures including kidney, liver, and central nervous system (CNS) [1].

Previous studies have shown that $\mathrm{Cd}$ administration cause motor hyperactivity [2], [3] increased aggressive behavior [4], and affects anxiety-like behavior [5], [6]. Effects of Cd in young and adult offspring of mothers exposed during pregnancy are still not clear according literature. It was demonstrated that low-level environmental cadmium exposure is associated with DNA hypomethylation in Argentinean women [7] and $\mathrm{Cd}$ exposure during embryogenesis causes embryo toxicity and long-term effects [8]. According to results by [3] Cd-related neurobehavioural effects during development may be a more sensitive parameter for $\mathrm{Cd}$ toxicity than renal dysfunction.

Dimethoate insecticide belongs to a class of nonpersistent pesticides, the organophosphates, which has its widespread use in many countries, to control wide variety of crop insects and flies in the external and domestic environments. Thus, human exposure to it can result from environmental, occupational, or accidental exposure [9].

Similarly to $\mathrm{Cd}$, various studies have suggested that 
exposure to organophosphate insecticides, including DM, are associated with increased anxiety [10] and damage of motor activity and performance [11]. Interestingly, these effects are associated with inhibition of the AChE enzyme since organophosphate insecticides are classic inhibitors of this enzyme [12] although other environmental agents, such as Cd for example, also inhibit their activity [13].

Cholinergic system plays important roles during development besides sustaining or modulating different aspects of CNS activity. The neurotransmitter acetylcholine (ACh) play an important role in many functions of both the central and peripheral nervous systems [14]. As Cd and DM can cause changes in AChE activity [12], [13], [15], [16] a good tool for better understand a relation between neurobehavioural effects by $\mathrm{Cd}$ and $\mathrm{DM}$ and altered cholinergic neurotransmission, would be to study the AChE enzyme, which is a selective biochemical biomarker of effect for the cholinergic system [17].

Recent findings indicate that many diseases occurring in young and adult ages may be associated with environmental factors during fetal life, as a consequence of metabolic plasticity of organisms in this period [18], [19]. These findings raise concerns, because the brain of mammals is particularly sensitive during individual development [20], [21]. Thus, environmental and food contaminants can reach the fetus and reprogram changes in central nervous system development of offspring which in turn may lead to an increased risk of dysfunctions in the long term or even permanently [22], [23].

Most environmental chemical exposures involve multiple rather than single chemicals and it is rarely possible to predict when and what kind of interactions will occur from multiple chemical exposures, especially when combining chemicals with different mechanisms of action. The combined effects of chemical agents, as heavy metals and pesticides, on human health, need be evaluated because human exposition occurs generally through mixtures, while regulatory assessment of neurotoxicity by these compounds is currently performed only on selected single substances.

Despite exist several literature reports about behavioral effects of $\mathrm{Cd}$ and $\mathrm{DM}$ individually, there is only one published study of our laboratory regarding $\mathrm{Cd}$ and $\mathrm{DM}$ combined toxicity on offspring development, in the short and long term, using low doses of these chemicals showing that this mixture affected memory in the offspring [24].

Currently there is a great concern about some of the contemporary neurological diseases such as Parkinson's and Alzheimer's, because they include different types of cognitive, motors, emotional, and social behavioral components, and already exists a body of evidences of that these neurobehavioral components in these diseases may have been related or influenced by environmental agents [25]-[28]. These findings and the lack of systematic studies enhance the necessity of research on mixtures of environmental agents of type metal and pesticide.

Therefore, the aim of the present study was to assess motor activity and social behavior during development of rats offspring exposed to cadmium and dimethoate mixture in the gestational period, and to assess the importance of the cholinergic system in the modulation of these behaviors, using AChE activity as a biomarker of effect.

\section{MATERIAL AND METHODS}

\section{A. Animals and experimental design}

All procedures for animal experimentation were approved by the Ethics Committee (protocol no 606/2014), Biosciences Institute of Botucatu, São Paulo State University, which is complied with international guidelines for the use of experimental animals.

For experiments male and female Wistar rats were obtained from the colony housed at the São Paulo State University and kept in standard rat cages (maximum of four animals per cage) and maintained at $21 \pm 2{ }^{\circ} \mathrm{C}$, on a $12 \mathrm{~h}$ light/dark cycle, and were given free access to water and rat chow, until animals reach 80 day old.

Mating was performed by placing, in the same cage, three females with a male. Females were considered fertilized when sperm were observed in vaginal secretion (considered the zero day of pregnancy). For treatments, sixty pregnant females were divided into four experimental groups $(\mathrm{N}=15)$ and received, during gestational period, one of the following treatments: filtered water plus $0,3 \mathrm{ml}$ saline, via gavage (control); cadmium acetate in filtered drinking water, $10 \mathrm{mg} / \mathrm{l} \mathrm{Cd}$ (Sigma-Aldrich of Brazil); dimethoate, via gavage, $4 \mathrm{mg} / \mathrm{kg}$ (Sigma-Aldrich of Brazil); cadmium plus dimethoate.

Doses of the compounds studied were selected based in previous literature findings. The $\mathrm{Cd}$ dose of $10 \mathrm{mg} / \mathrm{l}$ was chosen based in Antonio et al. [13] which demonstrated that this dose decreased AChE activity in 21 days old offspring without causing any apparent toxic effects in mothers. The DM dose of $4 \mathrm{mg} / \mathrm{kg}$ was chosen based in Srivastava and Raizada [29] which demonstrated that none toxic effect in pregnant females were observed up to doses of $30 \mathrm{mg} / \mathrm{kg}$.

Pregnant females were evaluated weekly during gestation period for: body weight gain, liquid and food intake, and clinical signs (convulsion, tremors, death), and behavior (aggression, nest formation and maintenance of puppies in it, handling and treatment of puppies). In the $20^{\circ}$ day gestation was determined their levels of $\mathrm{Cd}$ and $\mathrm{DM}$ in blood.

At birth pups were observed for number of pups/sex/mother, eventually the number of live/dead pups, the average weight, and changes in the macroscopic physical integrity. Then, pups were adjusted to six male per mother (female pups were used only to complete each litter to six pups, when necessary).

After weaning, motor activity, social behavior, and brain AChE activity were performed in the 30 and 80 post natal day (PND30 and PND80). For assessments one single pup chosen at random from each litter, to obviate possible biasing effects due to genetic homogeneity within litters, were grouped per treatment group.

\section{B. Assessment of motor activity}

\section{Assess of motor coordination using hole-board (HB):}

Motor coordination were evaluated using the apparatus described in [30] which consists of a square box $(28 \times 28 \times 20 \mathrm{~cm})$, taking the floor painted white and containing 81 holes of $2 \mathrm{~cm}$ diameter by $1 \mathrm{~cm}$ deep (arrangement of $9 \times 9$ ). An acrylic lid covers the box to allow viewing and/or filming inside the box. For each animal, the 
motor coordination was evaluated during $5 \mathrm{~min}$, according to the number of times the animals leg disappeared into a hole (paw-dip number).

Assess of spontaneous locomotor activity using open field arena $(\mathrm{OF})$ :

Spontaneous locomotor activity in OF was assessed according to the methodology described in Trombini et al. [31]. Quickly, apparatus consist of a wood box measuring $97 \times 32.5 \mathrm{~cm}$ (diameter $\mathrm{x}$ height). This was divided into three concentric circles, which were subdivided by painted black lines into 18 similar spaces. For locomotor activity observations, each rat was placed on center of the arena and for the next $3 \mathrm{~min}$ was scored ambulation frequency (number of floor units entered with the four paws).

\section{Assessment of social behaviors}

\section{Assess of anxiety-like behavior using OF and elevated plus maze (EPM):}

For observations in OF, each rat was placed on center of the arena and for the next 3 min was recorded the latency time to first passage and the number of total crossings by the center of arena.

The EPM task was conducted according methodology validated by Pellow and File [32] for the study of anxiolytic and anxiogenic drugs in rats, as described previously [31] and was assessed using an apparatus consisting of two open and two enclosed arms of equal length and width (50 x 10 $\mathrm{cm})$. The EPM task is based on the principle that exposure to an elevated and open arm maze leads to an approach conflict that is considerably stronger than that evoked by exposure to an enclosed maze arm. Thus, the percentage of total entries and time spent in closed arms provides a measure of anxiety or fear-induced inhibition of normal exploratory activity.

All apparatus (HB, OF, and EPM) used in behavioral tests were carefully cleaned with $5 \%$ ethanol before each rat was introduced, to remove traces of the previous animal.

\section{Aggressive behavior:}

This study used a model of aggression based on the resident-intruder paradigm [33]. This method allows the observation of social interaction and offensive behavior of the resident animal as well as the intruders defensive elements by reflecting intraspecific aggression [34]. The resident/intruder paradigm is a good predictive test for validating human aggression [35] and has the advantage of detecting even mild aggression involving minimal injury to the animals. To perform the test, resident animals were housed individually throughout the treatment period and evaluations. Intruder animals were housed grouped in cages, received no treatment and were used only once a day for the experiment and never returned to the same resident animal. Residents were housed one animal per cage and treated for 4 weeks. During this period their cages were not washed or exchanged, and during the last week the bedding in their cages was not changed. To assess aggression, an intruder animal was placed in the cage of a resident animal and their interaction for $900 \mathrm{~s}$ (15 $\mathrm{min})$ was recorded in tape. Recordings were later evaluated for the following observed parameters: latency to the first bite (LB, seconds), total number of attacks (NA), total duration of attack manifestations (DAM, seconds, including explosions of bite, lateral threats, maintenance of his paws over the other animal, and more intense grooming). The home territory defended by residents was the cage each animal since the first day of the experiment.

All tasks assessed in the present study were filmed for posterior quantification of parameters assessed.

\section{Biochemical assay}

\section{Cadmium and dimethoate dosage:}

Exposition of mothers to $\mathrm{Cd}$ and $\mathrm{DM}$ was confirmed through dosage in blood in the $20^{\circ}$ gestation day. Dosage of $\mathrm{Cd}$ and DM in brain of pups was realized at PND30 and PND80. Cd dosage used atomic absorption spectrometry, according Roberts \& Clark [36], and DM dosage used gas chromatography, according Van der Hoff \& Van Zoonen [37].

\section{Acetylcholinesterase dosage:}

After behavioral testing the animals were anesthetized using a 1:1 solution of $10 \%$ ketamine hydrochloride (Dopalen ${ }^{\circledR}$ Ceva, Brazil) and 2\% xylazine hydrochloride (Anasedan ${ }^{\circledR}$ Ceva, Brazil) and then they were decapitated, the brain was removed, separated sagittally into two halves, and the left half was used for measurement of brain acetylcholinesterase activity. The brain tissue was homogenized, and a sample of the brain homogenate was used for spectrophotometric dosage (Spectrophotometer Ultrospec 2000 - Pharmacia Biotech) of AChE activity (Biotech kit - Brazil).

\section{E. Statistical analysis}

Results obtained were analyzed using GraphPad Instat Software (San Diego, California, USA). Data were compared by the two-way analysis of variance (ANOVA); a Tukey-Kramer post hoc test was used for comparisons between means when ANOVA was significant at $\mathrm{p}<0.05$ level [38]. Values in figures and tables are presented as mean \pm standard error of the mean (S.E.M.).

\section{RESUlTS}

Mothers receiving Cd or DM not presented alterations of body weight gain, liquid and food intake, or clinical signs (tremors, convulsion, death), or altered behavior (data not shown).

Compared to the control group, in the treated groups there was no change in the pups weight at birth, number of pups per mother, as well as the sex of the pups per mother and the number of live and dead pups.

Table I shows the levels of Cd and DM in mothers in the $20^{\circ}$ gestation day confirming their exposition, and the result of Cd and DM dosage in brain of offsprings. It is possible to observe that while the DM was not detected in offspring at PND30 and PND80, the Cd was present in the animals in both, juvenile and adult age. 
TABLE I: CONCENTRATION OF CD AND DM IN BLOOD OF MOTHERS IN THE 20 GESTATION DAY (N=5 ANIMALS/GROUP) AND IN THE BRAIN OF OFFSPRING ( $\mathrm{N}=10$ ANIMALS/GROUP)

\begin{tabular}{|c|c|c|c|c|c|c|}
\hline \multirow{3}{*}{$\begin{array}{c}\text { Group } \\
\text { of treatment }\end{array}$} & \multirow{2}{*}{\multicolumn{2}{|c|}{$\begin{array}{c}\text { Mothers } \\
\text { (blood) }\end{array}$}} & \multicolumn{4}{|c|}{ Offspring (brain) } \\
\hline & & & \multicolumn{2}{|c|}{ PND30 } & \multicolumn{2}{|c|}{ PND80 } \\
\hline & $\begin{array}{c}\text { Cd } \\
(\mu \mathrm{g} / \mathrm{mL})\end{array}$ & $\begin{array}{c}\text { DM } \\
(\mu \mathrm{g} / \mathrm{L})\end{array}$ & $\begin{array}{c}\text { Cd } \\
(\mu g / g)\end{array}$ & $\begin{array}{c}\text { DM } \\
(\mu \mathrm{g} / \mathrm{g})\end{array}$ & $\begin{array}{c}\text { Cd } \\
(\mu \mathrm{g} / \mathrm{g})\end{array}$ & $\begin{array}{c}\text { DM } \\
(\mu \mathrm{g} / \mathrm{g})\end{array}$ \\
\hline $\mathbf{C t}$ & ND & ND & ND & ND & ND & ND \\
\hline Cd & $0.05 \pm 0.005^{*}$ & ND & $0.10 \pm 0.01 *$ & ND & $0.04 \pm 0.005^{*}$ & ND \\
\hline DM & ND & $50.2 \pm 5.50 *$ & ND & ND & ND & ND \\
\hline $\mathrm{Cd}+\mathrm{DM}$ & $0.06 \pm 0.002 *$ & $50.8 \pm 3.41 *$ & $0.11 \pm 0.009^{*}$ & ND & $0.05 \pm 0,007^{*}$ & ND \\
\hline
\end{tabular}

$\mathrm{Ct}=$ control; $\mathrm{Cd}=$ cadmium; $\mathrm{DM}=$ dimethoate; $\mathrm{Cd}+\mathrm{DM}=$ cadmium+dimethoate. Values express the mean $\pm \mathrm{S} . \mathrm{E} . \mathrm{M}$.

(ANOVA). ND= not detected, ${ }^{*} \mathrm{p}<0.05$ vs. $\mathrm{Ct}$.

\section{A. Motor activity evaluation}

Figure 1 A shows that exposition to Cd or DM single not altered motor coordination but when were administered in conjunct increased the paw-dip number indicating a decrease of the motor coordination in both PND30 and PND80. These results are characteristic of motor effect early and permanent on offspring. Figure $1 \mathrm{~B}$ shows that the treatments not modified spontaneous locomotor activity at PND30 or PND80.

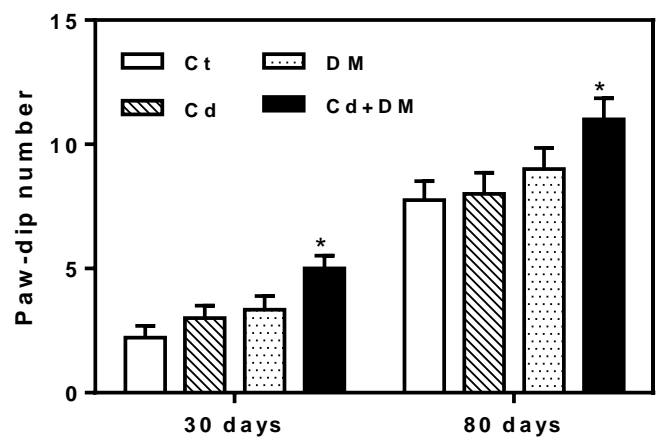

B

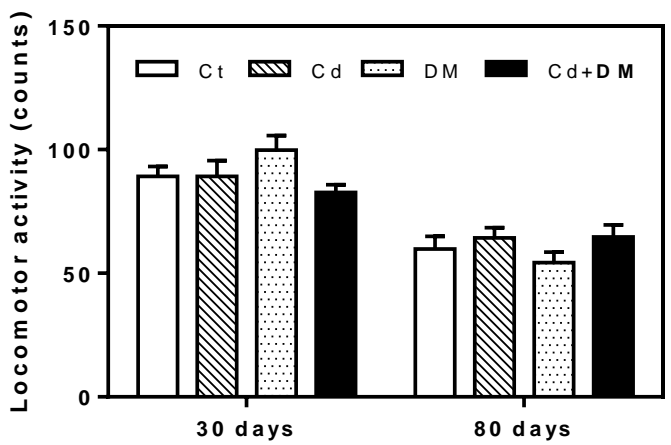

Fig. 1. Assessment of motor coordination in HB (A) and spontaneous locomotor activity in OF (B), in offspring at PND30 and PND80. ( $N=10$ animals/group). $\mathrm{Ct}=$ control; $\mathrm{Cd}=$ cadmium; $\mathrm{DM}=$ dimethoate;

$\mathrm{Cd}+\mathrm{DM}=$ cadmium + dimethoate. Values express the mean \pm S.E.M. (ANOVA). ${ }^{*} \mathrm{p}<0.05$ vs. Ct.

\section{B. Social behaviors evaluation}

Figure 2 shows that exposition to $\mathrm{Cd}$ or DM single not altered the time spent (A) and total entries (B) in closed arms but when were administered in conjunct caused an increase in the time spent (A) and in total entries (B) in closed arms at PND30. Already in PND80 while exposition only to $\mathrm{Cd}$ not modified the time spent (A) nor the total entries (B) in closed arms, exposition to DM and $\mathrm{Cd}+\mathrm{DM}$ increased the time spent (A) and the total entries (B) in closed arms. These results are suggestive of an anxiogenic effect by DM single or Cd and DM in conjunct. Here, results also indicate effect early and permanent on offspring.

Figure 3 shows that exposition to $\mathrm{Cd}$ and DM both single and in conjunct did not change the latency to the first bite (A) nor the total number of attacks (B) at PND30. Also is showed in the Fig. 3 that the total duration of attack manifestations was not changed by all treatments at PND30 and PND80. But, at PND80 the latency to the first bite was decrease and the total number of attacks was increased by $\mathrm{Cd}$ and DM exposure in conjunct. These results are suggestive of a late effect on the aggressive behavior.

A

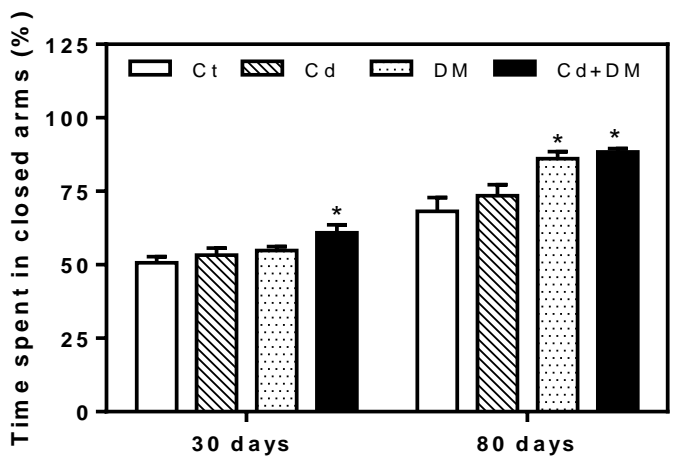

B

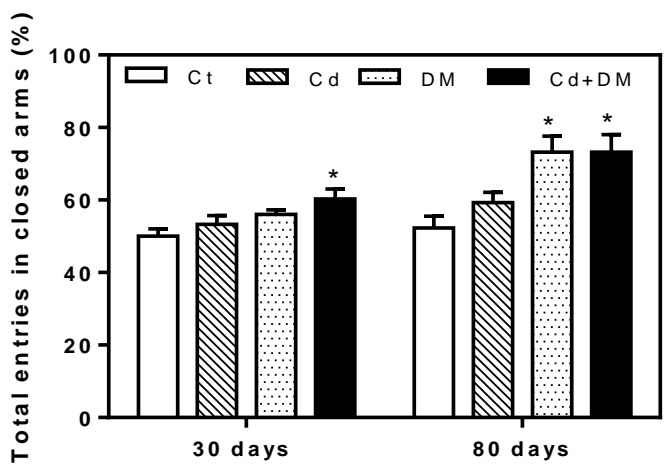

Fig. 2. Assessment of anxiety-like behavior in EPM through the percentage of time spent (A) and of total entries (B) in closed arms, in offspring at PND30 and PND80. ( $\mathrm{N}=10$ animals/group). $\mathrm{Ct}=$ control; $\mathrm{Cd}=$ cadmium; $\mathrm{DM}=$ dimethoate $\mathrm{Cd}+\mathrm{DM}=$ cadmium+dimethoate. Values express the mean \pm S.E.M. (ANOVA), ${ }^{*} p<0.05$ vs. Ct.

\section{Acetylcholinesterase activity}

Figure 4 shows that exposition to $\mathrm{Cd}$ and DM both single and in conjunct decreased the AChE activity in brain of offspring's at PND30 but not at PND80 although exposition to $\mathrm{Cd}$ and $\mathrm{DM}$ in conjunct had caused a decrease not significant of $21 \%$ at PND80. Also, it is possible to observe 
in Fig. 4 that the decrease of the AChE activity by exposition to the $\mathrm{Cd}$ and $\mathrm{DM}$ in conjunct is higher compared com the exposition to the $\mathrm{Cd}$ and DM single, suggesting an additive effect.

A - Latency to the first bite

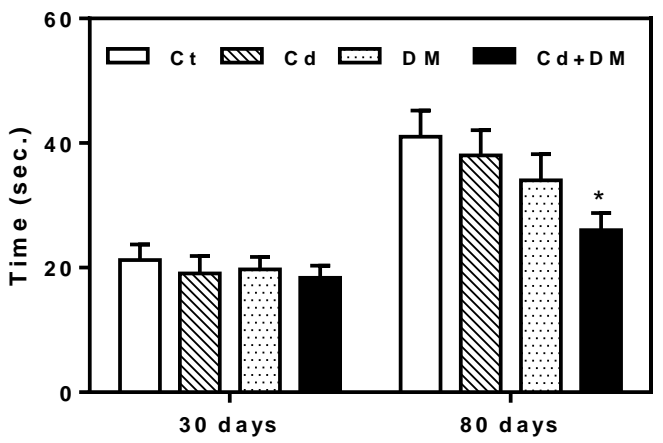

B - Total number of attacks

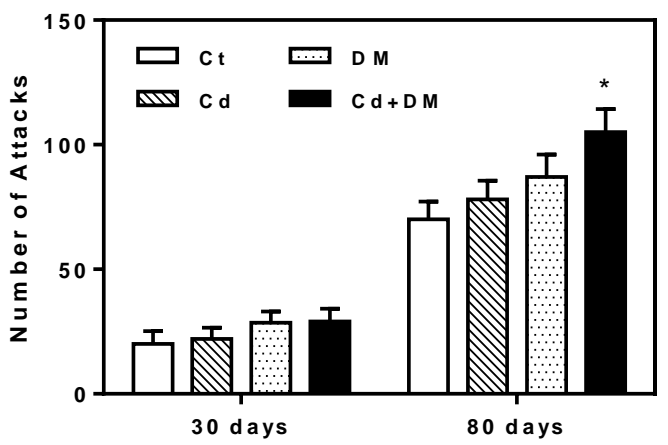

C - Total duration of attack manifestations

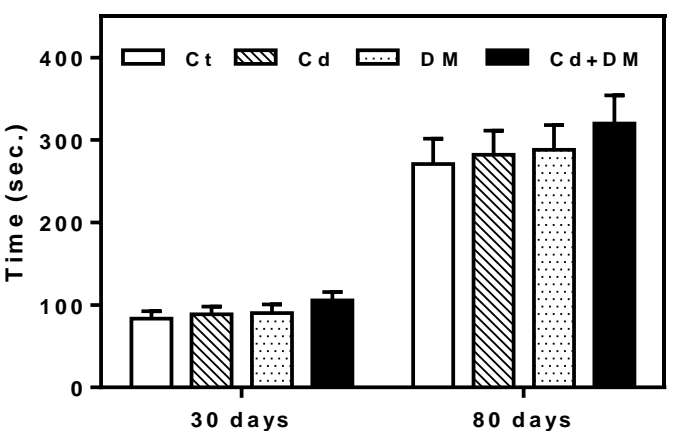

Fig. 3. Assessment of parameters related to aggressiveness behavior in offspring at PND30 and PND80 ( $\mathrm{N}=10$ animals/group). $\mathrm{Ct}=$ control;

$\mathrm{Cd}=$ cadmium; $\mathrm{DM}=$ dimethoate $\mathrm{Cd}+\mathrm{DM}=$ cadmium+dimethoate. Values express the mean \pm S.E.M. (ANOVA), ${ }^{*} \mathrm{p}<0.05$ vs. Ct.

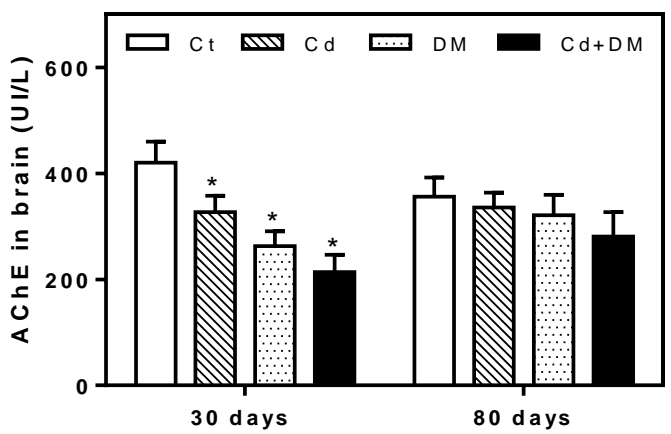

Fig. 4. Assessment of brain AChE activity in offspring at PND30 and
PND80 ( $\mathrm{N}=10$ animals/group). $\mathrm{Ct}=$ control; $\mathrm{Cd}=$ cadmium; $\mathrm{DM}=$ dimethoate; $\mathrm{Cd}+\mathrm{DM}=$ cadmium+dimethoate. Values express the mean \pm S.E.M. (ANOVA), ${ }^{*} \mathrm{p}<0.05$ vs. Ct.

\section{DISCUSSION}

The findings of the present study demonstrated that gestational exposure to $\mathrm{Cd}$ and $\mathrm{DM}$ in low doses alters motor activity and social behavior in offspring, during development indicating clearly an effect of fetal reprogramming. At same time, offspring presented inhibition of the activity of brain acetylcholinesterase enzyme suggesting the involvement of cholinergic nervous system in the observed effects.

Several scientific reports have observed that there are critical windows during the development. The presence of environmental agents in these periods perturbs the intrauterine environment and causes alterations (epigenetic, structural, or functional) that result in reprogramming in the post-natal life. Thus, low birth weight, childhood growth, and subsequent disease in adulthood have all been linked to several adverse environmental influences during early development [39].

In this sense, previous studies have suggested that gestational $\mathrm{Cd}$ exposure reprograms offspring development. Ronco et al. [40] observed that cadmium exposure during pregnancy reprograms cardiovascular development of the offspring which in turn may conduce to a long term increased risk of cardiovascular disease. Other studies shown that $\mathrm{Cd}$ is implicated in the induction of developmental neurotoxicity and cognitive dysfunction in both humans [41] and animals [42]. Additionally, gestational $\mathrm{Cd}$ exposure induced a decrease in brain enzymes activity, including AChE activity, in the offspring [14], [43].

In accordance with these findings in a previous study on gestational exposure to $\mathrm{Cd}$ and $\mathrm{DM}$ mixture we observed that offspring presented a deficit of memory during development, mainly in later age [24]. It would be important to study later whether these effects had the influence of oxidative stress, since both $\mathrm{Cd}$ and $\mathrm{DM}$ generate reactive oxygen species $[44,45]$.

In the present study we observed that offspring of mothers exposed only to $\mathrm{Cd}$ not presented alterations in the motor activity or social behavior studied, although a decrease in brain AChE activity in PND30 pups had occurred. This may be a consequence of the low dose level of $\mathrm{Cd}$ used in the study, although cadmium has been found in the brain of these pups, probably due to their cumulative action [46]. Pari and Murugavel [47] investigated the influence of $\mathrm{Cd}$ on cholinergic neurotransmission and observed an association between cholinergic $\mathrm{Cd}$ action and behavioral impairments in both animal models and humans exposed to $\mathrm{Cd}$.

In relation to DM, few previous studies have suggested that gestational exposure to DM is capable of cause harmful effects during offspring development. Farag et al. [48] observed that DM caused developmental toxicity through inhibition of the maternal and fetal AChE activities, and Abouamer et al. [49] observed that DM induced intrauterine 
growth retardations in mice. In our study, similar to what occurred in pups exposed to $\mathrm{Cd}$, offspring of mothers exposed only to DM not presented alterations of motor activity or in the state of aggressiveness but presented increased anxiety in the offspring at the PND80. As offspring exposed only to DM presented decrease in the AChE activity in brain of PND30 but not of PND80 pups, it is possible infer the possibility of that DM has caused an effect of epigenetic imprinting maintaining the effect in the long term.

The results obtained with the assessment of motor activity were interesting, since motor coordination was significantly reduced only in the offspring of the mothers who received combined exposure of $\mathrm{Cd}$ and $\mathrm{DM}$, while the spontaneous locomotion activity was not affected in any of the treatment groups. This result suggests clearly damage in motor activity and confirms that there was no bias in the hole-board evaluation, since increased locomotion may increase the probability of paw-dip number [31]. Also, it indicates that the mixture is more effective in causing neurotoxicity.

The conjunct of our data clearly indicates that $\mathrm{Cd}$ and DM acted in combination when these toxicants were given together. As the effect of $\mathrm{Cd}$ alone was not significant although it has decreased $(21 \%)$ AChE activity in brain, thus, we might think of an additive effect. According to [50] the term addition is used to describe situations whereby chemicals do not interact but act together to produce effects without enhancing or diminishing each other's actions. Overall, the damaging effects on motor and social behaviors were more accentuated in the offspring of mothers exposed to $\mathrm{Cd}+\mathrm{DM}$ regardless of the effect appearing at age of PND30 or PND80. These results reinforce the suggestion of that inhibition of the AChE activity is a probable pathway for the $\mathrm{Cd}+\mathrm{DM}$ induced developmental toxicity in rats.

Although Cd was detected in the brain of PND80 pups, the effect of the mixture is not due exclusively to $\mathrm{Cd}$ since he alone did not cause anything in the behaviors despite having decreased AChE activity in the pups' brains at PND30. Interestingly, it appears that the absence of DM in the pups brain at PND80 did not affected the onset of effects, but it is important remember that DM metabolite omethoate cause inhibition of AChE and it is ten times as toxic as DM [51]. Unfortunately for technical reasons it was not possible to quantify the concentration of omethoate in the brains of animals exposed to DM.

About the exposure of the pups to the $\mathrm{Cd}$ and $\mathrm{DM}$ mixture was observed that it decreased motor coordination and increased anxiety-like behavior in PND30 and PND80 pups in addition to stimulating aggression in the PND80 pups. Concomitantly, a decrease in brain AChE activity was observed, but only in PND30. It is possible that the mixture has caused an epigenetic imprinting on the cholinergic system, which was expressed as changes in motor activity and social behaviors in young and/or adult offspring. It is important that the next steps of the study investigate the occurrence of this epigenetic effect, since this proof would characterize the fetal reprogramming by exposure to the $\mathrm{Cd}$ and DM mixture.

Santafé et al. [52] observed that there is a close modulation of acetylcholine release that is performed by muscarinic receptor M1 of acetylcholine, in the motor nerve terminals in the neuromuscular junction, and which is related to the process of phosphorylation of protein quinase C. These observations can indicate the possibility of neuromuscular disorders and may also be involved in the process of impairment of motor incoordination in the present results. The inhibitory effect of $\mathrm{AChE}$ observed is due to $\mathrm{Cd}+\mathrm{DM}$ exposure and it can be associated to these neuromuscular dysfunctions leading to motor incoordination.

In mammals, activity of the cholinergic system is associated with motor nervous activity, such as motor coordination and ambulation, but little is known about the consequences of altered cholinergic neurotransmission in socially motivated behaviors as anxiety and aggression [53], [54].

Interestingly the results showed that in treatments with just Cd or DM the only observed effect was increased anxiety-like behavior in the DM group, and especially in the PND80 offspring. Our results do not still provide good subsidies to explain such results, however, there is a possibility that the inhibitory effect of DM on AChE, as it is stronger, is also the most determinant for the reprogramming effect of increased anxiety-like behavior. These findings are in accordance with Rohlman et al. [55] which demonstrated a correlation between neurobehavioral performance and biomarkers of organophosphorus pesticides exposure.

Agents capable to cause fetal programming are typically examined in relation to its negative health impact or pathological outcome on offspring phenotype [56]. However, in experimental studies, those effects are often examined using agents that are administered to animals at a high concentration, often outside of the normal physiological range or recommended doses. While this approach may be understandable and even preferable at an initial stage of research, there is evidence that those same agents given within a physiological range or tolerable intensity can mediate different long-term programming effects. In the present study it was demonstrated developmental effect by $\mathrm{Cd}$ and DM mixture, in low doses, which makes the observed effects even more worrying and worthy of attention, since the doses of exposure used are slightly close to those of the general population.

\section{CONCLUSION}

Present results provide, for the first time, direct experimental evidence supporting that joint exposure to cadmium and dimethoate in uterus of rats seems additive and it perturbs offspring development leading to harmful consequences on motor activity and social behavior, probably related to modulation of the cholinergic system. The present study suggests that added precautions regarding gestational exposure to metals and pesticide mixtures would be prudent to avoid the possibility of fetal reprogramming effect during development. 


\section{ACKNOWLEDGMENT}

We acknowledge the contribution of Ph.D. Alaor Aparecido Almeida, M.Sc. Fábio Iachel da Silva, respectively Pharmacist and Chemist at the Center of Toxicological Assistance (CEATOX), São Paulo State University (UNESP), Botucatu, São Paulo, Brazil and of Ph.D. Ana Angélica Henrique Fernandes, Researcher at the Department of Chemistry and Biochemistry, São Paulo State University (UNESP), Botucatu, São Paulo, Brazil. We also acknowledge the Coordination for the Improvement of Higher Education Personnel (CAPES, Brazil) for the financial support.

\section{REFERENCES}

[1] T.D. Zadorozhnaja, R.E. Little, R.K. Miller, N.A. Mendel, R.J. Taylor, B.J. Presley, et al., "Concentrations of arsenic cadmium, cooper, lead, mercury, and zinc in human placentas from two cities in Ukranine", J. Tox. Environ. Health, vol 61, pp.255-263, October 2000.

[2] M.T. Antonio, N. López, M.L. Leret, "Pb and Cd poisoning during development alters cerebellar and striatal function in rats", Toxicology, vol 176, pp.59-66, July 2002.

[3] K.P. Grawé, A. Teiling-Gårdlund, E. Jalkesten, A. Oskarsson, "Increased spontaneous motor activity in offspring after maternal cadmium exposure during lactation", Environ. Toxicol. Pharmacol., vol 17, pp.35-43, May 2004.

[4] S.G. Terçariol, A.A. Almeida, A.F. Godinho, "Cadmium and exposure to stress increase aggressive behavior", Environ. Toxicol. Pharmacol., vol 32, pp.40-45, March 2011.

[5] J.F. Gonçalves, A.M. Fiorenza, R.M. Spanevello, C.M. Mazzanti, G.V. Bochi, F.G. Antes, et al., "N-Acetylcysteine prevents memory deficits, the decrease in acetylcholinesterase activity and oxidative stress in rats exposed to cadmium", Chem. Biol. Interact., vol 186 pp.53-60, June 2010.

[6] P. Apostoli, S. Catalani, "Metal ions affecting reproduction and development", Met Ions Life Sci., vol 8, pp.263-303, January 2011.

[7] M.B. Hossain, M. Vahter, G. Concha, K. Broberg, "Low-level environmental cadmium exposure is associated with DNA hypomethylation in Argentinean women", Environ. Health Perspect. vol 120, pp.879-884, June 2012.

[8] T.M. Everson, D.A. Armstrong, B.P. Jackson, B.B. Green, M.R. Karagas, C.J. Marsit, "Maternal cadmium, placental PCDHAC1, and fetal development”, Reprod. Toxicol., vol 65, pp.263-271, August 2016.

[9] F. Sayim, "Dimethoate-induced biochemical and histopathological changes in the liver of rats", Exp. Toxicol. Pathol., vol 59, pp.237243, December 2007

[10] M. Samih, P.K. N'Go, S. Belaaouja, A.O. Touhami, A.O.T. Aham, "Effects of Dimethoate Exposure on Locomotor Activity and Anxiety-Like Behavior in Female Wistar Rat", Journal of Behavioral and Brain Science, vol 7, pp.484-496, October 2017.

[11] M. Valenzuela-Harrington, A. Gruart, J.M. Delgado-García, "Contribution of NMDA receptor NR2B subunit to synaptic plasticity during associative learning in behaving rats", European Journal of Neuroscience, vol 25, pp.830-836, February 2007.

[12] J.B. Braquenier, E. Quertemont, E. Tirelli, J.C. Plumier, "Anxiety in adult female mice following perinatal exposure to chlorpyrifos", Neurotoxicol Teratol, vol 32, pp.234-239, March-April 2010.

[13] M.T. Antonio, L. Corredor, M.L. Leret, "Study of the activity of several brain enzymes like markers of the neurotoxicity induced by perinatal exposure to lead and/or cadmium", Toxicol. Lett., vol 143, pp.331-340, August 2003.

[14] E. Scarr, "Muscarinic receptors: their roles in disorders of the central nervous system and potential as therapeutic targets", CNS Neurosci Ther., vol 18, pp.369-379, May 2012.

[15] H. Carageorgiou, V. Tzotzes, C. Pantos, C. Mourouzis, A. Zarros, S Tsakiris, "In vivo and in vitro effects of cadmium on adult rat brain total antioxidant status, acetylcholinesterase, $\left(\mathrm{Na}^{+}, \mathrm{K}^{+}\right)$-ATPase and $\mathrm{Mg}^{2+}$-ATPase activities: protection by L-cysteine", Basic Clin Pharmacol Toxicol, vol 94, pp.112-118, March 2004.

[16] J.F. Gonçalves, F.T. Nicoloso, P. da Costa, J.G. Farias, F.D. Carvalho, M.M. da Rosa, et al., "Behavior and brain enzymatic changes after long-term intoxication with cadmium salt or contaminated potatoes", Food and Chemical Toxicology, vol 50 pp.3709-3718, October 2012.

[17] R. Kroes, C. Galli, I. Munro, B. Schilter, L. Tran, R. Walker, et al, "Threshold of Toxicological Concern for Chemical Substances Present in the Diet: A Practical Tool for Assessing the Need for Toxicity Testing", Food and Chemical Toxicology, vol 38, pp.255312, February-March 2000.

[18] D.J. Barker, J.G. Eriksson, T. Forsen, C. Osmond, "Fetal origins of adult disease: strength of effects and biological basis", Int. J. Epidemiol., vol 31, pp.1235-1239, December 2002.

[19] P.D. Gluckman, M.A. Hanson, C. Pinal, "The developmental origins of adult disease", Matern. Child Nutr., vol 1, pp.130-141, June 2005.

[20] P. Grandjean, P.J. Landrigan, "Neurobehavioural effects of developmental toxicity", Lancet Neurol., vol 13, pp.330-338, March 2014.

[21] H. Palma-Gudiel, F. Cirera, F. Crispi, E. Eixarch, L. Fañanás, "The impact of prenatal insults on the human placental epigenome: A systematic review", Neurotoxicol. Teratol., vol 66, pp.80-93, MarchApril 2018.

[22] M.L. Leret, J.A.S. Millán, M.T. Antonio, "Perinatal exposure to lead and cadmium affects anxiety-like behavior", Toxicology, vol 186 pp.125-130, May 2003

[23] J.F. Shelton, E.M. Geraghty, D.J. Tancredi, L.D. Delwiche, R.J. Schmidt, B. Ritz, et al., "Neurodevelopmental disorders and prenata residential proximity to agricultural pesticides: The CHARGE study", Environ. Health Perspec., vol 122, pp.1103-1109, October 2014.

[24] F. Anselmo and A.F. Godinho, "Gestational exposure to cadmium and dimethoate, in low dose, individually or in mixture, modulates memory behavior during rat offspring development", in Diseños en la moderna Investigación Universitaria, J.E.G. Vallés, T.P. Otero, Ed. McGraw-Hill Interamericana de España S.L., Madrid, 2016, ch. 6, pp. 69-81

[25] J. Campdelacreu, "Parkinson's disease and Alzheimer disease: environmental risk factors", Neurologia, vol 29, pp.541-549, June 2012.

[26] T. Parrón, M. Requena, A.F. Hernández, R. Alarcón, "Association between environmental exposure to pesticides and neurodegenerative diseases", Toxicol. Appl. Pharmacol., vol 256, pp.379-385, November 2011

[27] J.R. Richardson, A. Roy, S.L. Shalat, R.T. von Stein, M.M. Hossain B. Buckley, et al., "Elevated serum pesticide levels and risk for Alzheimer disease", JAMA Neurol., vol 71, pp.284-290, March 2014.

[28] D. Yan, Y. Zhang, L. Liu, N. Shi, H. Yan, "Pesticide exposure and risk of Parkinson's disease: Dose-response meta-analysis of observational studies", Regul. Toxicol. Pharmacol., vol 96, pp.57-63 July 2018.

[29] M.K. Srivastava, R.B. Raizada, "Development of technical dimethoate in rats: maternal and fetal toxicity evaluation", Indian J. Exp. Biol., vol 34, pp.329-333, April 1996.

[30] A.F. Godinho, S.L. Stanzani, F.C. Ferreira, T.C. Braga, M.C. Silva, J.L. Chaguri, et al., "Permethrin chronic exposure alters motor coordination in rats: Effect of calcium supplementation and amlodipine", Environ. Toxicol. Pharmacol., vol 37, pp.878-884, March 2014

[31] T.V. Trombini, C.G. Pedroso, D. Ponce, A.A. Almeida, A.F Godinho, "Developmental lead exposure in rats: is a behavioral sequel extended at F2 generation", Pharmacol. Biochem. Behav., vol 67, pp.743-751, April 2001.

[32] S. Pellow, S.E. File, "Anxiolytic and anxiogenic drug effects on exploratory acitivy in an elevated plus maze: a novel test of anxiety in the rat", Pharmacol. Biochem. Behav., vol 24, pp.525-529, March 1986.

[33] S.F. Long, M.C. Wilson, K.J. Sufka, W.M. Davis, "The effects of cocaine and nandrolone co-administration on aggression in male rats", Prog. Neuro- Psychopharmacol. Biol. Psychiatry, vol 20, pp.839-856, July 1996.

[34] J.M. Koolhaas and B. Bohus, "Animal models of human aggression", in Animal Models in Psychiatry II , vol. 2, A. Alan, A.A. Boulton, et al. (Eds.), Ed. Humana Press, Clifton, NJ, 1991, pp. 249-271.

[35] B. Oliver and L.J. Young, "Animal models of aggression", in Neuropsychopharmacology: The Fifth Generation of Progress, K.L. Davis, D. Charney, et al. (Eds.), Digital Library, Philadelphia, PA 2002, ch. 118, pp.1699-1708.

[36] C.A. Roberts, J.M. Clark, "Improved determination of cadmium in blood and plasma by flameless atomic absorption spectroscopy", Bull. Environ. Contam.Toxicol., vol 36, pp.496-499, March 1986. 
[37] G. Van der hoff, P. Van Zoonen, "Trace analysis of pesticides by gas chromatography”, J. Chromatogr. A., vol 843, pp.301-322, May 1999.

[38] G.W. Snedecor and W.G. Cochran, Statistical Methods, $8^{\mathrm{a}}$ ed., Wiley, Iowa, 1991.

[39] I.C. McMillen, J.S. Robinson, "Developmental origins of the metabolic syndrome: prediction, plasticity and programming", Physiol. Rev., vol 85, pp.571-633, April 2005.

[40] A.M. Ronco, M. Montenegro, P. Castillo, M. Urrutia, D. Saez, R Zepeda, et al., "Maternal exposure to cadmium during gestation perturbs the vascular system of the adult rat offspring", Toxicology and Applied Pharmacology, vol 251, pp.137-145, March 2011.

[41] G. Schoeters, E. Den Hond, M. Zuurbier, R. Naginiene, P. van den Hazel, N. Stilianakis, et al., "Cadmium and children: exposure and health effects", Acta Paediatr Supp., vol 95, pp.50-54, October 2006.

[42] O. Faroon, A. Ashizawa, S. Wright, P. Tucker, K. Jenkins, L. Ingerman, et al., "Toxicological Profile for Cadmium". Agency for Toxic Substances and Disease Registry (US). Agency for Toxic Substances and Disease Registry (ATSDR) Toxicological Profiles, September 2012

[43] C. Liapia, V. Stolakis, A. Zarros, K.M. Zissis, J. Botis, H. AlHumadi, et al., "Gestational exposure to cadmium alters crucial offspring rat brain enzyme activities: The role of cadmium-free lactation”, Environ. Toxicol. Pharmacol., vol 36, pp.835-839, August 2013.

[44] Y. Sharma, B.M. Somia, B. Irshad, G. Datta, T.D. Dograa, "Effects of acute dimethoate administration on antioxidant status of liver and brain of experimental rats", Toxicology, vol 206, pp.49-57, January 2005.

[45] J. Thompson, T. Doi, E. Power, I. Balasubramanian, P. Puri, J. Bannigan, "Evidence against a direct role for oxidative stress in cadmium-induced axial malformation in the chick embryo", Toxicology and Applied Pharmacology, vol 243, pp.390-398, December 2009.

[46] S. Satarug, S.H. Garrett, M.A. Sens, D.A. Sens, "Cadmium, environmental exposure, and health outcomes", Environ. Health Perspect., vol 118, pp.182-190, February 2010.

[47] L. Pari, P. Murugavel, "Diallyl tetrasulfide improves cadmium induced alterations of acetylcholinesterase, ATPases and oxidative stress in brain of rats", Toxicology, vol 234, pp.44-50, May 2007.

[48] A.T. Farag, T.A.Z. Karkour, A. El Okazy, "Developmental Toxicity of Orally Administered Technical Dimethoate in Rats", Birth Defects Res B Dev Reprod Toxicol, vol 77, pp.40-46, February 2006.

[49] W. Abouamer, W. Abu-Shaeir, S. Bakry, "Dimethoate Induced Intrauterine Growth Retardations in Mice", American-Eurasian Journal of Toxicological Sciences, vol 5, pp.85-93, December 2013.

[50] V. Rizzati, O. Briand, H. Guillou, L. Gamet-Payrastre, "Effects of pesticide mixtures in human and animal models: An update of the recent literature", Chemico-Biological Interactions, vol 254, pp.231246, July 2016.

[51] A. Hassan, S.M. Zayed, M.R. Bahig, "Metabolism of organophosphorus insecticides-XI: Metabolic fate of dimethoate in the rat", Biochem. Pharmacol., vol 18, pp.2429-2438, October 1969.

[52] M.M. Santafé, M.A. Lanuza, N. Garciia, J. Tomàs, "Muscarinica autoreceptors modulate transmitter release through protein kinase $\mathrm{C}$ and protein Kinase A in the rat motor nerve terminal", Eur. J. Neurosci., vol 23, pp.2048-2056, April 2006.

[53] O. Kiehn, "Locomotor circuits in the mammalian spinal cord", Annu Rev Neurosci., vol 29, pp.279-306, July 2006.

[54] M.B. Sokolowski, "Social interactions in "simple" model systems", Neuron., vol 65, pp.780-794, March 2010.

[55] D.S. Rohlman, W.K. Anger, P.J. Lein, "Correlating neurobehaviora performance with biomarkers of organophosphorus pesticide exposure", Neurotoxicology, vol 32, pp.268-276, December 2010.

[56] D.R. Kim, T.L. Bale, C.N. Epperson, "Prenatal programming of mental illness: current understanding of relationship and mechanisms", Curr. Psychiatry Rep., vol 17, January 2015.

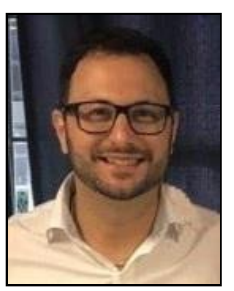

Ph.D. Fábio Anselmo was born in Conchas, SP, Brazil (November 12, 1986). Graduated in Biological Sciences (2010) from São Paulo State University (UNESP), Botucatu, SP, Brazil. He has a master's degree (2016) and doctorate (2020) in Pharmacology and Biotechnology from São Paulo State University (UNESP), Botucatu, SP, Brazil. He has experience in the areas of Pharmacology, Biotechnology and Toxicology, with an emphasis on Neurotoxicology, mainly in neurotoxic effects resulting from exposure to pesticides and heavy metals.

He is currently Biology teacher in basic education (Prof. Manoel Patrício do Nascimento school, Botucatu, SP, Brazil.) and he is writing a postdoctorate project in the Biochemistry field. To quote some of his remarkable publications:

[1] A.F. Godinho, A.C.O. Souza, C.C. Carvalho, D.F. Horta, D. deFraia, F. Anselmo, J.L. Chagury, C.A. Faria, "Memory impairment due to fipronil pesticide exposure occurs at the $\mathrm{GABA}_{\mathrm{A}}$ receptor level, in rats", Phisiology \& Behavior, vol 165, pp.28-34, June 2016

[2] F. Anselmo and A.F. Godinho, "Gestational exposure to cadmium and dimethoate, in low dose, individually or in mixture, modulates memory behavior during rat offspring development", in Diseños en la moderna Investigación Universitaria, J.E.G. Vallés, T.P. Otero, Ed. McGraw-Hill Interamericana de España S.L., Madrid, 2016, ch. 6, pp. 69-81.

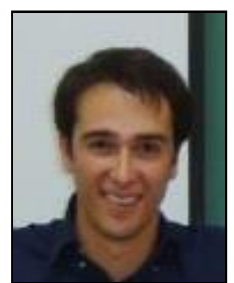

M.Sc. Daniel França Horta was born in Lorena, SP, Brazil (October 12, 1990). Graduated in Veterinary Medicine (2012) from State University of Londrina (UEL), Londrina, PR, Brazil. He has residency in Preventive Veterinary Medicine (2015) from State University of Londrina (UEL), Londrina, PR, Brazi and a master's degree (2017) in Pharmacology and Biotechnology from São Paulo State University (UNESP), Botucatu, SP, Brazil.

$\mathrm{He}$ is currently Federal Agricultural Tax Auditor MAPA, Joaqum Távora, PR, Brazil. To quote some of his remarkable publications:

[1] J.L. Chagury, A.F. Godinho, D.F. Horta, V.H. Gonçalves-Rizzi, J.S. Possomato-Vieira, R.A. Nascimento, C.A. Dias-Junior, "Exposure to fipronil elevates systolic blood pressure and disturbs related biomarkers in plasma of rats", Environmental Toxicology and Pharmacology, vol 42 , pp.63-68, December 2015

[2] A.F. Godinho, A.C.O. Souza, C.C. Carvalho, D.F. Horta, D. deFraia, F. Anselmo, J.L. Chagury, C.A. Faria, "Memory impairment due to fipronil pesticide exposure occurs at the $\mathrm{GABA}_{\mathrm{A}}$ receptor level, in rats", Phisiology \& Behavior, vol 165, pp.28-34, June 2016

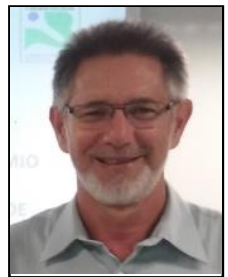

Ph.D. Antonio Francisco Godinho was born in Botucatu, SP, Brazil (December 1, 1954). Graduated in Biological Sciences (1981) from São Paulo State University (UNESP), Botucatu, SP, Brazil. He has a master's degree (1985) and doctorate (1989) in Pharmacology from University of São Paulo (USP), Ribeirão Preto, SP, Brazil. He works in the area of Toxicology, mainly in the following subjects: neurotoxicity, behavioral toxicity, heavy metals and pesticides.

He is currently Researcher II at the Toxicological Assistance Center (CEATOX), Institute of Biosciences, São Paulo State University (UNESP), Botucatu, SP, Brazil. To quote some of his remarkable publications:

[1] P.R.G. Terçariol, A.F. Godinho, "Behavioral effects of acute exposure to the insecticide fipronil", Pesticide Biochemistry and Phisiology, vol 99, pp.221-225, March 2011.

[2] S.G. Terçariol, A.A. Almeida, A.F. Godinho, "Cadmium and exposure to stress increase aggressive behavior", Environmental Toxicology and Pharmacology, vol 32, pp.40-45, July 2011. 